- The GDC sets a dangerous precedent in allowing Clinical Dental Technicians independent practice.

- Academic Heads of Departments are responsible for the decline in standards of undergraduate teaching.

- Specialist societies, especially the BSSPD, should have had more input into the training of CDTs.

\title{
The future for removable prosthodontics in the UK - a personal opinion
}

\section{J. Wilson ${ }^{1}$}

In allowing Clinical Dental Technicians (CDTs) to practise complete denture prosthodontics independently the General Dental Council (GDC) has set a dangerous precedent that could threaten the future integrity of the 'dental team'. In bemoaning the decline in standards for undergraduate teaching of removable prosthodontics the academic specialists, and the BSSPD, only have themselves to blame. It can only be hoped that, once established, Clinical Dental Technicians will raise the woefully low standard of removable prosthodontics in the UK.

I read, with mixed emotions, (anger, sadness, bewilderment) the editorial on the Teaching of removable prosthodontics in the UK (Br Dent J 2006; 201: 129) and wondered whether the timing was deliberate rather than coincidental. The mentioned British Society for the Study of Prosthetic Dentistry (BSSPD) conference took place in March 2006. 31 July 2006 was a momentous date for the dental profession. On that day the GDC not only legalised CDTs but also gave them the right to practise as independent clinicians, rather than as members of the much vaunted 'dental team'. It seemed that the GDC had finally caved in to pressure from the denturists without and the Dental Care Professionals (DCPs) within. However, as for its assertion that it consulted 'widely' I would like to know where, when and with whom? Surely with the

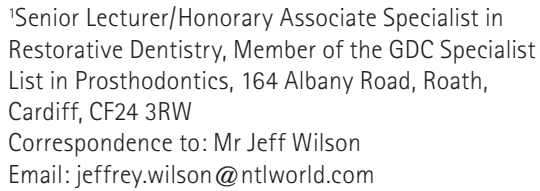

BSSPD, the recognised specialist body concerned with removable prosthodontics; or perhaps with the British Prosthodontic Conference; or even with the 360 (approx.) members of the GDC Specialist List in Prosthodontics? Did the GDC consult directly with all registered general dental practitioners, who are most likely to be affected by these legislative changes? If it did I am not aware of any such consultation having occurred. Where was the publicity or communication? In my opinion the GDC acted irrationally, irresponsibly and without proper consultation.

I then wondered where the editor and all those worthy people in the so called 'representative group' from the BSSPD had been hiding all this time. The editorial appeared in the first edition of the $B D J$ following the date for registration of all DCPs, but nowhere did the editorial mention CDTs - who will now, presumably, have the opportunity to lead the study and practice of removable prosthodontics to higher levels of competence and excellence! Those concerned academics will no longer need to worry about teaching complete denture prosthetics as it should only be a matter of time before this topic is removed from the undergraduate dental curriculum. Forgive me for saying it, but the editorial was riddled with inaccuracies, non-sequiturs and, in my humble opinion, nonsense!

I then assumed that the editorial may have been based on a report from the representative group - in which case I may owe the $B D J$ editor an apology. However, this would imply that the $B D J$ editor is more privileged than the ordinary BSSPD members who have not yet had the opportunity to read such a report from this group.

The editorial concludes with this representative group vowing to lessen any negative impact on undergraduate teaching in the future. The cry goes up 'too late - the horse has already bolted, the damage already done!' Who were the members of this representative group? They were none other than the academic 'Heads of Departments' of the prosthetics teachers in the (mainly) undergraduate dental schools. But why are these leading members of academe suddenly bemoaning the decline in the standard of undergraduate removable prosthodontic teaching when they, themselves, must be held responsible for that very teaching and, by implication, the decline?

I was a delegate attending the AGM of that BSSPD conference. Some delegates suggested that perhaps the BSSPD, 
including the academic Heads of Departments, had suddenly woken up to the fact that CDTs were almost upon us and we should be doing something about it. Where have they all been hiding too, I wondered? When a suggestion from the floor was made that the BSSPD should make representations to the GDC in this respect I was shocked by the response of the Chairman when he responded that he was 'not minded to do so'! I place the blame for the lack of involvement of the specialist societies squarely with the presidents of those societies, who have obviously done little or nothing to involve themselves or their societies in this debate - which has been going on for several years.

With respect to the CDTs - and one must admire them for their persistence - I have absolutely no problem in welcoming them as DCPs, but only if they are properly trained, competent and regulated. Badly made complete dentures can, after all, cause harm. As I understand it (from anecdotal information gained from technician colleagues, some of whom are practising denturists in the UK), the clinical training for UK denturists of the 'George Brown School' consists of three weeks spent in Canada making complete dentures for one or two people. This is hardly comparable with the three or so clinical years spent by most dental undergraduates in the UK. Granted, they do not spend all that time managing edentulous patients, but do gain an enormous amount of clinical experience compared with only three weeks. I also feel strongly that, as DCPs, CDTs should be part of the dental team with the dentist as team leader and taking overall responsibility. The dental team and team working is one of the fundamental aims of the current GDC, so I wonder why the ability for CDTs to practise independently was 'sneaked in', as it was never part of the original proposals. In my opinion some form of clinical examination (similar to the International Qualifying Examination for foreign dentists) to validate the clinical training of CDTs should have been instituted. Unfortunately this ability to practise independently sets a very dangerous precedent, for it will only be a matter of time before CDTs are pressing to be allowed to make partial dentures independently, then possibly even more. Following such a lead, other DCPs would, no doubt, want to practise independently as hygienists and therapists. The irony is that some practising denturists do not carry out their own technical work but send their clinical work to a technical laboratory.

What about the NHS? Will enabling legislation be passed to allow CDTs to charge edentulous patients the NHS fee for making a set of complete dentures? Will Primary Care Trusts contract local CDTs to make a number of complete dentures? I doubt it, as practising denturists seem to charge as much, if not more than their dentist colleagues on a private basis. Even under the new contract's remuneration scheme, I would suggest that it is not really worth trying to make a set of dentures on the NHS.

Apparently, the GDC will not allow CDTs to practise in the UK until they are deemed competent to do so. This means they will have to obtain a 'diploma' after following a course of study to be organised by the Kent Deanery and regulated by the Faculty of General Dental Practitioners of the Royal College of Surgeons of England. I would like to know where this was all set up. Who was involved/ consulted and what qualifies these particular 'experts' to certify the CDTs? When asked what topics will be taught on this diploma does more clinical experience feature? No - everything else but clinical experience. To prepare CDTs for independent clinical practice they will be taught the theory of radiology, governance and cross infection control. I would argue that there is nothing more important than clinical experience. However, this also adds to the danger of the precedent in that it gives CDTs the right to diagnose with virtually no clinical experience whatsoever.

The GDC has therefore devalued removable prosthodontics but, more importantly, is showing disregard for the oral health of the edentulous. It has also insulted recognised specialists in removable prosthodontics, especially the members of its own prosthodontics specialist list. Why has it done this - to satisfy a demand for complete dentures in the UK? Hardly, at a time when the specialists are saying that there is a dwindling number of edentulous, that the average age of edentulism is increasing and that the difficulty of managing the edentulous patient is increasing.

And what for the future? I sincerely hope that CDTs will join (and be welcomed by) the specialist societies rather than keeping themselves to themselves, will want to participate in raising the standards of removable prosthodontics and will work with dentists and the dental team rather than working in isolation. However, I doubt this will happen. Since originally penning this article I attended the 2007 conference of the American Prosthodontic Society under the presidency of our own Professor Harold Preiskel (the first non-American president of this society). At their AGM they formally admitted Dental Technologists as full members of the Society. The European Prosthodontic Association has always welcomed as members anyone with an interest in prosthodontics. Let us hope that the BSSPD will now be proactive in encouraging dental technologists and especially CDTs to join its ranks.

In my opinion, the best place to train CDTs would have been alongside their undergraduate dental student and dental technician colleagues in dental schools and hospitals. However, it seems that there is little will for this either on the side of the CDTs or, regrettably, on the side of the deans of dental schools (with the notable exception of Sheffield).

31 July 2006 was a sad day for dentists, prosthodontists, and especially the edentulous, thanks to the GDC. My only hope is that our new CDT colleagues will start to raise the declining standard of complete denture prosthetics in the UK. 